is certainly less objectionable; whetber in a sanitary, an economical, or a sentimental aspect, than the retention of the crude sewage within in habited areas.

The remaining conclusions relate to the subject proper of the inquiry, and we quote them together:-

"(j) That, as far as we have been able to ascertain, none of the existing modes of treating town sewage by deposition and by chemicals in tanks appear to effect much change beyond the separation of the solids and the clarification of the liquid. That the treatment of sewage in this manner, however, effects a cunsiderable improvement, and, when carried to its greatest perfection, may in some cases be accepted.

"(6) That, as far as our examinations extend, none of the manufactnred manures made by manipulating towns' refuse, with or without chemicals, pay the contingent costs of such modes of treatment, neither has any mode of dealing separately with excreta, so as to defray the cost of collection and preparation by a sale of the manure, been brought under our notice.

(7) That town sewage can best and mnst cheaply be disposed of and purified by the process of land irrigation for agricultural purposes, where local conditions are favourable to its application, but that the chemical value of sewage is greatly reduced to the farmer by the fact that it must be disposed of day hy day throughout the entire year, and that its volume is generally greatest when it is of the least service to the land.

" (8) That land irrigation is not practicable in all cases; and therefore other modes of dealing with sewage must be allowed.

"(9) That towns situated on the sea-coast, or on tidal estuaries, may be allowed to turn sewage into the sea or estuary below the line of low water, provided no nuisance is caused; and that such mode of getting rid of sewage may be justified on the zcore of economy."

The full significance of these conclusions can only be rigbtly understood by reading along with them the last section of the Report, especially the ldst two paragraphs. A more pathetic outpouring of bucolic grief we have rarely read. Moreover, the section is in tbe strangest contrast with the offensive dogmatism of the other parts of the Report. The argument of the section amounts to this:Agriculture, never specially lucrative, has of late years afforded "very little profits." But such minimised profits as are possible to agriculture will probably be most surely secured by sewage farms, notwithstanding the special difficulti+s attaching to their working, if certain as yet unachieved conditions can be obtained for them.

In a previous part of the Repors ibe attempts which bave been made to supplement wet, systems of sewage disposal wi'b so-called dry systems are descrited as an economical failare. It would now appear from this Report that any sy sem yet devisud, except the system which pours its sewage into the nearest stream, stands in the came category, and that there is but litile mose bove of comparitive econmic success in a uniform system than in a combined system of sewage disposal. Under these circumstances, the tone taken by the Commititee in its gratuitous remarks on sys ems of excrem+nt disposal other than by water-carriage is as astonikhing as unjustifithle, whether regarded in an economical or in a sani ary light. In the latter aspectthe sanitary-the Committee treats excreta as of no more consideration in the question than sonp suds (p 18 et seq) ThH ureat nortbren towne, in dealing with this matter, alm first at removing the known most injurwous filth from the serage, and dealing with it in a manuer which will reoder it less harmful as things go in thise towns, and somewhat profichle in the sense of diminishing the enst of removal. This aspret of the question dors not appear to have been prisent to the miuds of the Committre at any time. It is idle here to argue the mecbanical advantages of water-car. rixge as compared with land-carriage. This is a local qurstinn solelg. The dry refuse of a trow has to be remived as weil as the wet rrfuse. The systematic removal of this dry refuse is just as important eanitarily as the gysterratic flowing away of the wet refuse. Whether it is desirab e to take away excremental mat'ers with the dry or with the wet is a question which local knowledge and experien.r can alone drtermine. Of the sanitary aspects of the $t w o$ questions thre is juat as much to be said in favcur of the one as of the other. Here again the Committee is wholly astray, and the important relations of the sub. ject to local self-health government are ignored in its discussion of it. The Committee would clearly narrow the question of sewage disposal in towns to a dogmatically taught principle. Its Report proves conclusively that the only reasonable hope we have of ever getting master of the complicated diffonlties besetting sewage-disposal is by encouraging local thought and locally conceived action on the suhject.

The blunders of the Report as to fact are not less remark. able tban the blunder as to the policy of sewage disposal. At p. xxvi. we are told that fermenting sewage is not dan. gerous to health to the extent its offensiveness might be taken to indicate. At p. xxxi. we are told that "sewage is injurious in proportion to its age and putridity." In several places, indeed generally, sewage passed into the sea or a tidal river is described as " wasted"; in the " conclusions" such a disposal is "justified on the score of econcmy." In the interpolated remarks on epidemics we read that " recent inquiries show that modern diseases of malignant types, such as typhus(!) and cholera, generate out of putrid refuse and gross neglect of sanitary works and operations." This written for a great Government Department in the year of grace 1876 ! There is much more to the same effect in the Report, and we would ask our readers to contrast its conclusions with the conclusions arrived at by the $\mathrm{C} / \mathrm{m}$ mission held under Mr. Stansfeld's presidency, at the Society of Arts, on the health and sewage of towns, in June, 1876, given in the Appendix (p. 129). With such a summary as this before it, even a Committee of the Local Guvernment Bivard might have been expected to show a clearer insight in to the subject of sewage-disposal than that manifested in the present Report.

\section{TREATMENT OF ANEURISM.}

\section{To the Editor of THE LANCET.}

SrR,-The article on aneurism which appears in your issue of the 20th inst. will be read with much interest by all sur. geons, as the treatment by the elastic bandage to which it refers promises to be both simple and efficacious. It however contains one statement to which exception may be taken. You say " the elastic bandage is the only metbod (except in. jection of bæmostatics) which confessedly aims at the forma. tion of passive blood-clots." It is now more than ten years since Dr. Kurray of Newcastle successfully applied the rapid pressure treatment to a case of abdominal aneurism. Mr. C. G. Wheelbouse has since cured a case of inguinal aneurism by the same method, and there are several other cases on record in which the treatment has been adopted. Two years ago I modified this proceeding by cutting down on the subclavian artery and applying temporary compression by means of a pair of artery forceps. In all these cases the object has been to secure the formation of a passive and not an active clot.

The modus operandi of this treatment is, $I$ think, not always alike. In some cases, as in that mentioned by you as reported by Dr. Ririd, the cure is due to the complete plugging of the aneurism and its proxim tl opening. Sometimes, bowever, as in Mr. Wheelbouse's and my own cases, there is a return of pulsation which continues for one or two days. When this occurs, as 1 stated in my paper on the subject which appeared in the Mrdico-Cbirurgieal Transactione, "the coegulation is sudden, and probably commences soon after the application of the pressure. The aneuriem is filled by a clot formed out of the blood that was in it at the time the pressure was applied. 'This elot, like any other in or out of the body, slowly contracts; for a time the walls of the sac contract round it, but occasionally it will shritk more quickly than the walls, and the pressure being removed from the supplying artery, the blood will pass between the clot and the wall, causing a return of pulsation. The blond will, however, have much d fficulty in passing through tbe limited space left in the sac; fibrin will be deposited from it, and the cure ermpleted."

I must. apol' gise for the length of this letter, which I hope yon will consider is justified by the importance of the subject.-I am, Sır, your ohedient servant,

Park-square, Leeds, Jan. 20th, 1877. 